\title{
The correlation between gear contact friction and ball on disc friction measurements
}

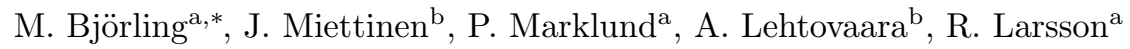 \\ ${ }^{a}$ Division of Machine Elements, Department of Engineering Science and Mathematics, \\ LuleåUniversity of Technology, Luleå, SE-97187 Sweden \\ ${ }^{b}$ Group of Tribology and Machine Elements, Department of Materials Science, Tampere \\ University of Technology, P.O. Box 589, 33101 Tampere, Finland
}

\begin{abstract}
Running experiments with full-size gearboxes from the actual application has the advantage of giving realistic results in terms of power losses. The drawback is extensive costs, lengthy testing, and the difficulty in differentiating between load dependent and load independent losses, and which losses are coming from the gears, seals, bearings or synchronizers. In this work, the correlation between friction measurements conducted in a ball-on-disc machine and friction measurements conducted in a back-to-back gear rig is investigated. The correlation between the gear tests and the ball-on-disc tests were reasonably good in terms of absolute values, and the shape of the friction curves were similar, indicating that the ball-on-disc measurements to a large extent are capturing the behavior of the gear contact.
\end{abstract}

Keywords: FZG, EHL, gears, friction, lubrication, ball-on-disc

\section{Nomenclature}
$\epsilon_{g} \quad$ Addendum contact ratio of gear
$\epsilon_{p} \quad$ Addendum contact ratio of pinion
$\epsilon_{t} \quad$ Contact ratio

\footnotetext{
* Corresponding author

Email address: marcus.bjorling@ltu.se (M. Björling)
}

Preprint submitted to Tribology International

June 14, 2018 


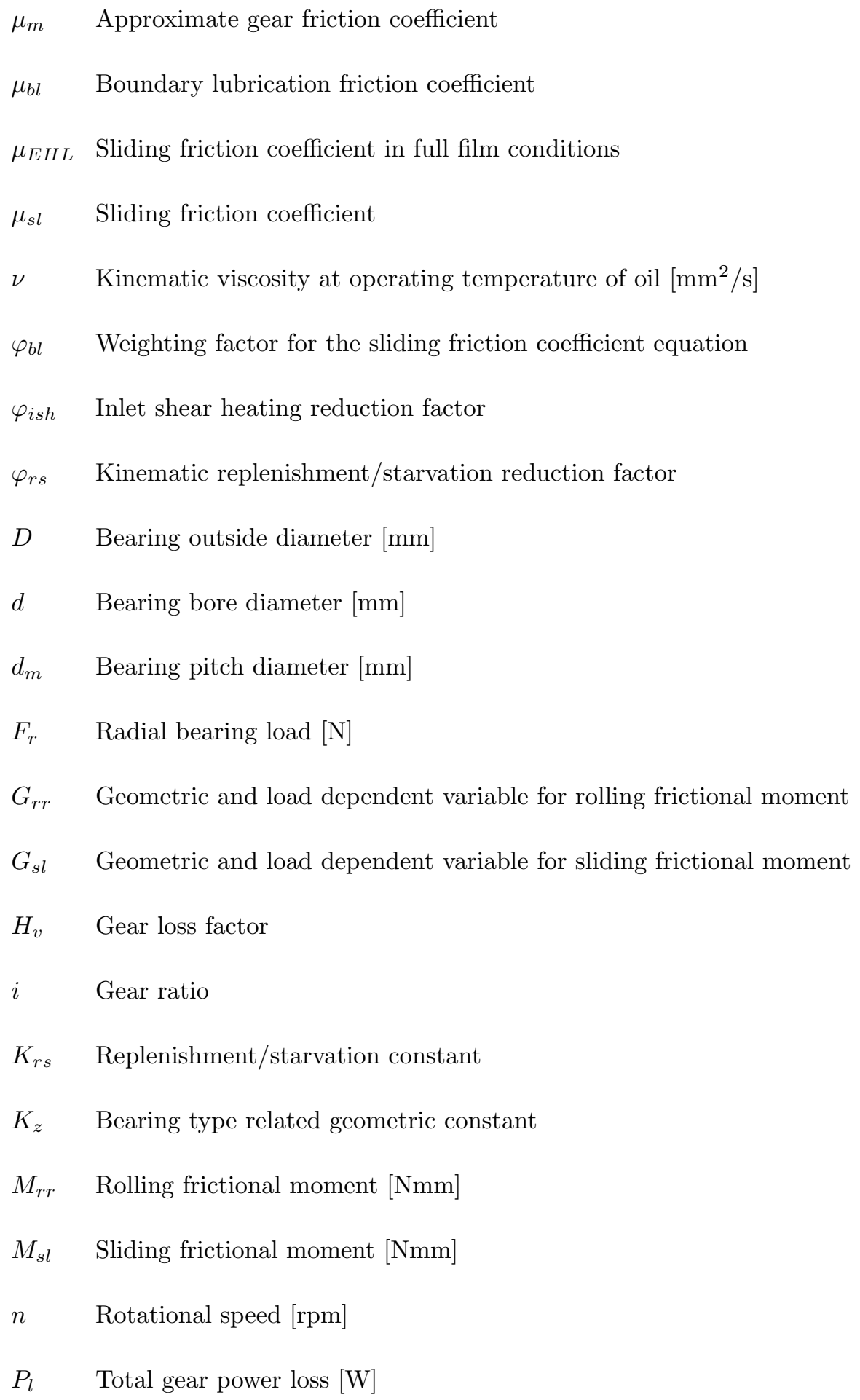


$P_{m} \quad$ Gear mesh power loss [W]

$P_{t} \quad$ Total transmitted power $[\mathrm{W}]$

$P_{b l} \quad$ Load dependent bearing power loss [W]

$P_{n l} \quad$ Load independent gear power loss [W]

$R_{1} \quad$ Geometric constant for rolling frictional moment

$S_{1} \quad$ Geometric constant for sliding frictional moment

$z \quad$ Number of gear teeth

\section{Introduction}

Reducing energy consumption and emissions have been a priority in the industrialized world for a long time, and even more so during the last 5-10 years. With the exception of bringing new technologies and solutions to the market, constant development is carried out to improve current technology. The automotive market has faced increasing restrictions in terms of emissions and has therefore spent large amounts of money on research and development. Rising fuel prices and increased environmental concern also make the customers more prone to purchase more fuel efficient vehicles. It has been assessed that 33 $\%$ of the fuel energy in a car is used to overcome friction, and that $7-18 \%$ of these friction losses originates from the transmission [1]. In heavy road vehicles and buses, $33.5 \%$ of the fuel energy is used to overcome friction, and $13 \%$ of these losses originates from the transmission 2]. The losses in a gear transmission can be devided into two categories; load dependent and load independent losses. The load independent losses are typically viscous losses due to oil churning and are mostly governed by lubricant viscosity, density and the geometrical design of gears and housing. The load dependent losses are due to friction in the rolling and sliding interfaces between the mating gear teeth, and are influenced by a large numbers of parameters. The total gear contact friction losses are ranging between 4.5 and $55 \%$ depending on the design and use of the transmission 
[3, 1]. Most gears are operating in the elastohydrodynamic lubrication (EHL) regime and the friction originating from these kinds of contacts are the matter of interest in this paper.

Running experiments with full size gearboxes from the real application has the advantage of giving realistic results in terms of power losses depending on lubricant type, load, speed and operating temperature. The drawbacks are extensive costs, lengthy testing, and the difficulty in differentiating between load dependent and load independent losses, and which losses are coming from the gears, seals, bearings or synchronizers. Even when a gear pair is rotating at a constant speed, several parameters are changing along the line of action between the meshing teeth, such as load, entrainment speed, and slide to roll ratio (SRR). When running tests with gears and being successful in removing all other sources of losses, only an average friction coefficient can be obtained. To remedy this problem and allow more detailed studies of gear losses both numerical and experimental methods have been used.

Several researchers have solved the numerical EHL problem to be able to predict, and understand gear friction. Such studies include both smooth [4, 5] and rough surfaces [6, 7, 8, A reliable and accurate numerical prediction model for gear contact friction would be the best alternative since the number of tests would be kept at a minimum, saving both time and money. However, EHL is a complex field, and there are as far as the authors knows no models with such true predictive capabilities to date [9. Due to the severe running conditions in many gearboxes, highly additivated lubricants are often used which also puts demands on the numerical models to include tribochemical effects which is a tremendous challenge.

As an alternative to numerical predictions, many authors have used twindisc machines to simulate power loss in gear contacts [10, 11, 12, 13, 14, 15]. By controlling the rotational speeds of two rollers in contact, the same entrainment speeds and SRRs can be achieved as in the line of action of the gear system that are simulated. This approach is cheaper and less time consuming than running full gear tests, and gives more detailed information regarding gear 
contact friction along the line of action. The twin disc is seen as suitable for mimicking a gear contact also due to the fact that both twin disc, spur and helical gears to some extent operate with line contacts. A ball on disc tribotester do not suffer from the same aligning problems encountered in a twin disc machine using disc profiles creating a pure line contact, and may be available at research facilities not having a twin disc machine. It is however unclear if it is possible to correlate the friction coefficient in the circular contact in a ball on disc tribotester to the line contact in the spur gear contact. The purpose of this work is to investigate the correlation between friction measurements conducted in a ball on disc machine with friction measurements conducted in a FZG gear test rig. In addition, using the earlier presented concept of friction mapping [16], a method is proposed to predict the friction coefficient in an arbitrary spur gear pair from a minimum of measurements in a ball-on-disc machine.

\section{Overall Methodology}

The following sections cover the test rigs, test specimens and lubricants used in the experiments. It also contains information about how the experiments were performed and how the data was processed and evaluated.

\subsection{Ball-on-disc tribotester}

The experiments were carried out with a Wedeven Associates Machine (WAM) 11, ball on disc test device. The lubricant is supplied at the centre of the disc in an oil dispenser that distributes the lubricant across the disc surface. The lubricant is circulated in a closed loop from the oil bath, through a peristaltic pump to the oil dispenser at the centre of the disc. The peristaltic pump is delivering approximately $180 \mathrm{ml} / \mathrm{min}$. Three thermocouples are used in the test setup, one located in the oil bath, one in the outlet of the oil supply and one trailing in the

oil film close to the inlet region of the ball on disc contact. A more thorough description of the test rig and its features is presented in previous work [16]. 


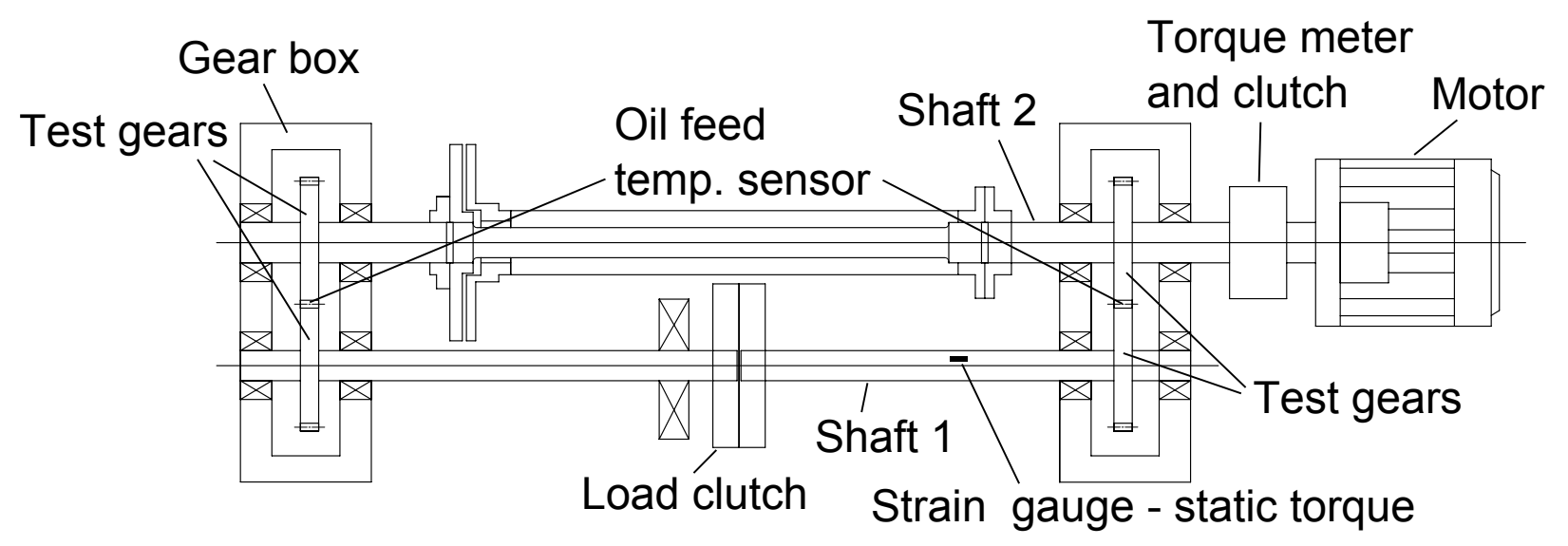

Figure 1: FZG test rig.

\subsection{Gear test rig}

A modified FZG test rig was used for the gear tests, as depicted in Figure 1 The test gears, described in section 2.3 were located in two separate housings with their own lubrication system with a capacity of 25 liters each. The gears were spray lubricated with a flow rate of 2.0 liters per minute directed in the entry side of the mesh. The loading of the gears were done by applying a torque on shaft 1 with the help of a rod and dead weights. The corresponding strain caused by the twist of the shaft was measured with full bridge strain gauge system. The power circulating design of the test rig means that the electric motor was only compensating for the energy equivalent to the losses in the system. However, the gear friction losses were calculated by the friction moment measured by a torque meter on shaft 2 .

\subsection{Test specimens and lubricants}

The test gears are made of case hardened steel, 21 NiCrMo2-2. The gears were case hardened to a depth of $1.1 \pm 0.5 \mathrm{~mm}$ and a hardness of $58 \pm 2 \mathrm{HRC}$. The test gears were subjected to grinding and polishing, down to a surface roughness of around $30 \mathrm{~nm}$ RMS measured with a stylus mechanical profilometer. This gives a combined RMS roughness for the gear pair of approximately 


\begin{tabular}{lc}
\multicolumn{2}{c}{ Table 1: Test gear geometry } \\
\hline Number of teeth & 20 \\
Pressure angle $\left[^{\circ}\right]$ & 20 \\
Gear Ratio & 1 \\
Centre distance $[\mathrm{mm}]$ & 91.5 \\
Normal module $[\mathrm{mm}]$ & 4.5 \\
Profile shift & 0.176 \\
Face width $[\mathrm{mm}]$ & 20 \\
Contact ratio & 1.45 \\
Addendum contact ratio & 0.725 \\
\hline
\end{tabular}

$42 \mathrm{~nm}$. Both pinion and gear have the same properties as shown in Table 1 which means that the gear ratio is 1 .

The ball-on-disc tests were performed with specimens made of DIN 100Cr6 (AISI 52100) bearing steel. The specimens have been measured to a surface roughness, RMS of $25 \mathrm{~nm}$ for the balls and $35 \mathrm{~nm}$ for the discs, which gives a combined roughness of approximately $43 \mathrm{~nm}$. The surface roughness measurements were conducted in a Wyko NT1100 optical profilometer system from Veeco. The measurements were performed using 10x magnification and $1 \mathrm{x}$ field of view. The balls are grade 20 with a 13/16 inch $(20.63 \mathrm{~mm})$ outer diameter and a hardness of about 60 HRC. The discs have a 4 inch $(101.6 \mathrm{~mm})$ outer diameter, a circumferential grind (before polish) and are through hardened to about 60 HRC.

The experiments were performed with three commercially available, fully formulated transmission oils whose properties are shown in Table 2 They are all synthetic oils with a PAO base.

\subsection{Gear test procedure}

The gear tests were performed at two different oil feed temperatures for each oil, 40 and $70^{\circ} \mathrm{C}$ and with a torque of $302 \mathrm{Nm}$ and $0 \mathrm{Nm}$. Before starting the measurements the lubrication systems were filled with 50 liters of the test oil and the rig was run with a $302 \mathrm{Nm}$ torque at a speed of $1250 \mathrm{rpm}$ for 1 hour for lubricant temperatures to stabilize and to warm up all components in the 
Table 2: Lubricant properties

\begin{tabular}{lccc}
\hline Name & Emgard MTF 4250 & Shell Spirax S6 AXME & Statoil Gearway S5 \\
\hline Classification & $75 \mathrm{~W}-90$ & $75 \mathrm{~W}-90$ & $75 \mathrm{~W}-140$ \\
Density @ $15^{\circ} \mathrm{C}\left[\mathrm{kg} / \mathrm{m}^{3}\right]$ & 879 & 878 & 872 \\
Kinematic viscosity @ $40^{\circ} \mathrm{C}\left[\mathrm{mm}^{2} / \mathrm{s}\right]$ & 140 & 115 & 190 \\
Kinematic viscosity @ $100^{\circ} \mathrm{C}\left[\mathrm{mm}^{2} / \mathrm{s}\right]$ & 18.4 & 15.2 & 25 \\
Dynamic viscosity @ $40^{\circ} \mathrm{C}[\mathrm{mPas}]$ & 123 & 101 & 166 \\
Dynamic viscosity @ $100^{\circ} \mathrm{C}[\mathrm{mPas}]$ & 16 & 13 & 22 \\
Oil type & Synthetic, PAO & Synthetic, PAO & Synthetic, PAO \\
\hline
\end{tabular}

test rig. The rig was then run with zero load at $1250 \mathrm{rpm}$ for one hour for the gear teeth to cool down. The rotational speed was now set to $750 \mathrm{rpm}$, still with zero load, and the measurements were started. After 15 minutes the speed was increased by $250 \mathrm{rpm}$, and after another 15 minutes increased by another $250 \mathrm{rpm}$ until the maximum speed of $2000 \mathrm{rpm}$ was reached. At this point the rig was stopped, and $302 \mathrm{Nm}$ torque was applied and the procedure was repeated from 750 to $2000 \mathrm{rpm}$ in steps of 250 each 15 minutes. The lubricant temperature, measured with thermocouples located in the oil feed at the gear mesh, were typically deviating less than $\pm 1^{\circ} \mathrm{C}$ during the tests. Before filling up with a new lubricant the lubrication system, gears and housings were thoroughly cleaned with heptane and left to dry over night.

The total power loss $P_{l}$ in a gear transmission is divided into load dependent losses and load independent losses. The load dependent losses are divided into mesh losses, $P_{m}$, and load dependent bearing losses, $P_{b l}$, while the load independent losses, $P_{n l}$, includes oil churning, seal friction and bearing losses at zero load. The total power loss can thus be expressed as:

$$
P_{l}=P_{m}+P_{n l}+P_{b l}
$$

By running the test rig with zero load, the load independent losses can be assessed, while running the rig with full load gives the total power loss. To be able to calculate the mesh dependent power losses, which is of main interest in this study there is also a need to assess the load dependent bearing losses. The 
load dependent power losses for the SKF 6406 deep groove ball bearings were calculated as [17]:

$$
P_{b l}=\left(M_{r r}+M_{s l}\right) \frac{2 \pi n}{60}
$$

where $M_{r r}$ is the rolling frictional moment, and $M_{s l}$ is the sliding frictional moment. $M_{r r}$ is calculated as:

$$
M_{r r}=\varphi_{i s h} \varphi_{r s} G_{r r}(\nu n)^{0.6}
$$

with:

$$
\begin{gathered}
\varphi_{i s h}=\frac{1}{1+1.84 \times 10^{-9}\left(n d_{m}\right)^{1.28} \nu^{0.64}} \\
\varphi_{r s}=1 / e^{\left[K_{r s} \nu n(d+D) \sqrt{\frac{K_{z}}{2(D-d)}}\right]}
\end{gathered}
$$

and:

$$
G_{r r}=R_{1} d_{m}^{1.96} F_{r}^{0.54}
$$

where $n$ is the rotational speed, $\nu$ the kinematic viscosity at operating temperature of the oil, $D=90 \mathrm{~mm}, d=30 \mathrm{~mm}, d_{m}=60 \mathrm{~mm}, K_{r s}=3 \times 10^{-8}, K_{z}=$ 3.1 , and $R_{1}=3.6 \times 10^{-7} . M_{s l}$ is calculated as:

$$
M_{s l}=G_{s l} \mu_{s l}
$$

with:

$$
\begin{gathered}
G_{s l}=S_{1} d_{m}^{-0.26} F_{r}^{5 / 3} \\
\mu_{s l}=\varphi_{b l} \mu_{b l}+\left(1-\varphi_{b l}\right) \mu_{E H L}
\end{gathered}
$$

and: 


$$
\varphi_{b l}=\frac{1}{e^{2.6 \times 10^{-8}(n \nu)^{1.4} d_{m}}}
$$

where $\mu_{b l}=0.15, \mu_{E H L}=0.04$ and $S_{1}=2.43 \times 10^{-3}$. When the mesh losses are calculated it is possible to compute an approximate average friction coefficient, $\mu_{m}$, based on a method presented by Michaelis and Höhn [18]:

$$
\mu_{m}=\frac{P_{m}}{P_{t} H_{v}}
$$

where $P_{t}$ is the total transmitted power and $H_{v}$ the gear loss factor given by:

$$
H_{v}=\frac{\pi}{z_{1}} \frac{i+1}{i}\left(1-\epsilon_{t}+\epsilon_{p}^{2}+\epsilon_{g}^{2}\right)
$$

where $z$ is the number of teeth, $i$ the gear ratio, $\epsilon_{t}$ the contact ratio, $\epsilon_{p}$ the addendum contact ratio of the pinion, and $\epsilon_{g}$ the addendum contact ratio of the gear.

\subsection{Correlation methodology}

The purpose of this study was to create conditions in the ball-on-disc test rig similar to the gear tests and compare the friction data between the tests. For this reason, the surface roughness were similar for the ball on disc specimens, and the gears. An analytic geometric model of the gear contact was used to calculate the maximum hertzian pressure with $302 \mathrm{Nm}$ of torque to approximately 1.24 GPa. The same model was also used to calculate SRR and entrainment speed along the line of action. The SRR in a gear contact is independent of rotational speed and was calculated to range from -1.1 to 1.1 in the gears used in this investigation. Since both pinion and gear have the same geometry the entrainment speed is constant along the line of action, but dependent on the rotational speed of the gears. The lowest rotational speed tested was $750 \mathrm{rpm}$ which corresponds to an entrainment speed of $1.37 \mathrm{~m} / \mathrm{s}$ while the highest speed of $2000 \mathrm{rpm}$ gives an entrainment speed of $3.66 \mathrm{~m} / \mathrm{s}$.

The ball on disc tests were performed with the same three oils as the gear tests and at the same temperatures. In the gear setup the contact pressure is 
changing along the line of action due to changes in effective radius, but also since the load is sometimes carried by only one tooth engagement and otherwise by two teeth engaging. To be able to use the earlier introduced concept of friction mapping [16] all tests in the ball on disc machine were performed with a load of $76 \mathrm{~N}$, equivalent to a maximum hertzian pressure of $1.24 \mathrm{GPa}$ which is the same as the maximum load calculated for the gear contact. Another simplification was made using only positive values for SRR, where in the actual gear contact, the SRR has opposite signs from going into contact (approach), to the pitch point, compared to from the pitch point going out of contact (recess).

Friction data for various entrainment speeds and SRRs were measured with the ball on disc test rig in a range that spans the minimum and maximum values calculated for the gear contact at the different rotational speeds as detailed in Table 3. A triangle based linear interpolation method were used to create a friction map for a specific lubricant at a specific pressure for a range of entrainment speeds and SRRs. One of the six 2D friction maps are shown in Figure 2 where friction coefficient measured in the ball on disc test rig is plotted as contours of entrainment speed and SRR. The figure also contains projections of the corresponding entrainment speeds and SRRs for three different rotational speeds, 750, 1250 and $2000 \mathrm{rpm}$, for the gear pair investigated in this work. Included in the figure is also the corresponding entrainment speeds and SRRs for a FZG type $\mathrm{C}$ gear pair at $2300 \mathrm{rpm}$ where the entrainment speed is not constant along the line of action. The FZG type C pattern is only included as an example, and has not been used in any tests performed in this article. The friction map can be seen as a look-up-table for an arbitrary rotational speed of a gear pair. The line of action were divided into 200 data points in the friction map for a specific rotational speed and used to calculate a mean friction coefficient that was compared to the mean friction coefficient obtained from the same rotational speed in the gear test. 


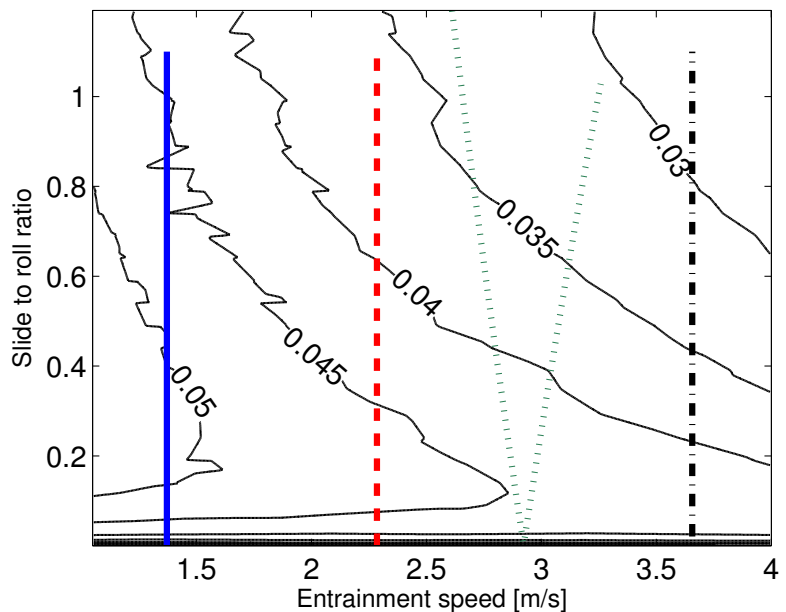

Figure 2: Example of friction map with corresponding entrainment speeds and SRRs along the line of action for tested gear pair at $750 \mathrm{rpm}$ (solid line), tested gear pair at $1250 \mathrm{rpm}$ (dashed line), tested gear pair at $2000 \mathrm{rpm}$ (dashed/dotted line) and FZG type C gear pair at $2000 \mathrm{rpm}$ (dotted line) measured in a ball on disc test rig.

\subsection{Ball on disc test procedure}

The ball on disc test device was used to generate friction data from a relatively broad range of operating conditions where one test cycle covers entrainment speeds between 1 and $4 \mathrm{~m} / \mathrm{s}$ and SRRs from 0.0002 to 1.2. Both ball and disc specimens were cleaned with heptane and ethyl alcohol before starting the experiments for each of the test cases. Before starting the experiments for each test case, the test device was warmed up to the desired operating temperature during approximately 60 minutes with lubricant circulation over both ball and disc to ensure thermal stability. When a stable temperature was reached a $76 \mathrm{~N}$ load was applied which is equivalent to $1.24 \mathrm{GPa}$ maximum Hertzian pressure and the machine was calibrated for pure rolling by adjusting spindle angle and positioning of the ball to ensure a condition of no spinning. These settings were then held constant for 20 minutes to ensure a mild run-in. Subsequently the test cycle was started. The test cycle contains several loops where SRR is held constant for each loop and the entrainment speed is ramped from 4 to $1 \mathrm{~m} / \mathrm{s}$. 


\begin{tabular}{lc} 
Table 3: Investigated conditions in ball on disc rig \\
\hline Temperature & 40 and $70{ }^{\circ} \mathrm{C}$ \\
Contact load & $76 \mathrm{~N}$ \\
Maximum hertzian pressure & $1.24 \mathrm{GPa}$ \\
Entrainment speed, $U_{e}$ & $1-4 \mathrm{~m} / \mathrm{s}$ \\
Slide to Roll Ratio, SRR & $0.0002-1.2$ \\
Oils & See Table 2 \\
\hline
\end{tabular}

In the first loop the SRR is held at 0.0002 and is then continuously increased with each loop until it reaches 1.2. The temperature of the oil bulk and fluid adhered at the disc surface was typically deviating less than $\pm 1.5^{\circ} \mathrm{C}$ from the target temperatures of 40 and $70{ }^{\circ} \mathrm{C}$ during testing.

\section{Results and discussion}

Figure 3 shows the change in SRR along the line of action going from approach (gear flank position 0), to the pitch point (gear flank position 100) and recess (gear flank position 200). Figure 4 shows the friction coefficients along the line of action for the gear pair at three different rotational speeds originating from the ball on disc measurements using the Emgard oil at $40^{\circ} \mathrm{C}$. Each rotational speed corresponds to an entrainment speed, and a set of SRRs as shown in figure 2. As the gear flanks first comes into contact, the SRR is at its highest value which leads to extensive thermal softening of the lubricant thus leading to low friction coefficients $[9,19$. The friction coefficients are then gradually increasing as the SRR decrease following the line of action towards the pitch point, thus leading to reduced thermal softening and instead a behaviour dominated by shear thinning and the limiting shear stress of the lubricant. At the lowest SRRs close to the pitch point the friction coefficient is rapidly decreasing due to the low shear rates the oil is subjected to at low sliding. When the pitch point is passed the SRR is again gradually increased following the same behaviour following the line of action towards the recess. The friction coefficients are generally lower at the higher entrainment speeds, an effect attri- 
buted to thicker oils films reducing the shear rates in the lubricant film. Higher entrainment speeds also leads to higher sliding speeds causing additional thermal softening, and possibly less asperity interactions due to the thicker oil films [9, 19]. For the ball on disc tests, the minimum film thickness was calculated to $180 \mathrm{~nm}$ at the highest temperature and the lowest entrainment speed for the lubricant with the lowest viscosity. For the same lubricant and temperature combination the film thickness was calculated to range from 135-155 nm along the line of action in the gear contact. These film thicknesses are significantly larger than the combined roughness of the surfaces in the ball on disc and gear contacts of 43 and $42 \mathrm{~nm}$ respectively. However, the film thickness calculation did not include shear thinning and therefore the actual film thickness may be substantially lower. Most likely, the majority of the tests were performed in full film lubrication, with the possible exception of the thinnest oil at the highest temperature and lowest speeds.

It should be mentioned that in most gear applications, superfinished gears are not used. Gears that has a larger roughness will to a bigger extent work in mixed and boundary lubrication opposed to the superfinished gears used in this study.

The mean value of the friction coefficients measured in the ball on disc rig along the line of action for a specific entrainment speed with a specific lubricant and temperature was used for comparison with the corresponding case at a specific rotational speed in the FZG test rig.

The results from the ball on disc friction measurements and the FZG tests are shown in Figs. 5 and 6 for the oil temperatures of 40 and $70^{\circ} \mathrm{C}$ respectively. The most important observation is that the ranking of the oils are the same in both test rigs, at both oil temperatures. It is clear that the lowest contact friction is achieved with the Gearway oil that has the highest viscosity, while the highest contact friction is achieved with the Spirax oil having the lowest viscosity. This is the case for both 40 and $70^{\circ} \mathrm{C}$. However, it should be mentioned that these differences may not solely depend on the viscosities of the lubricant, but also other properties, such as the limiting shear stress, and different additive 


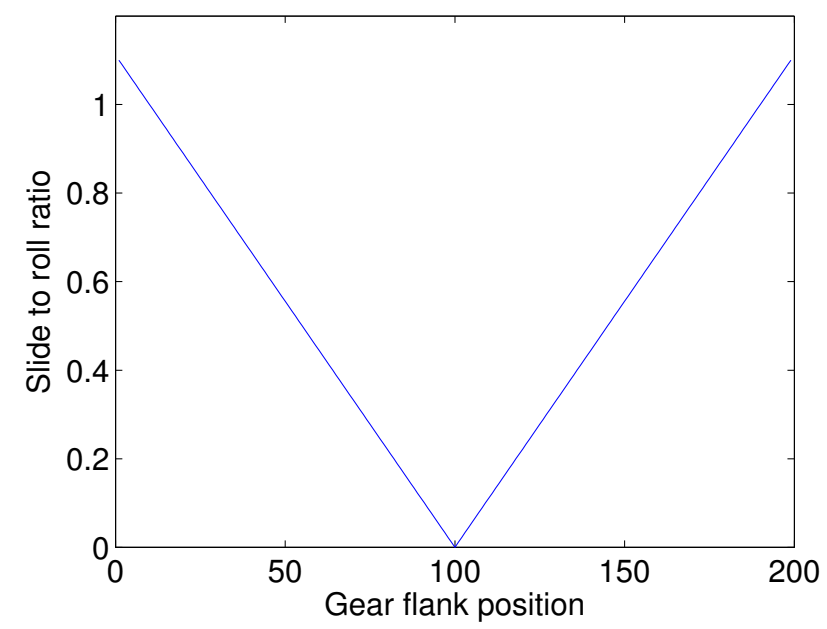

Figure 3: Change in SRR along the line of action using only positive values of SRR.

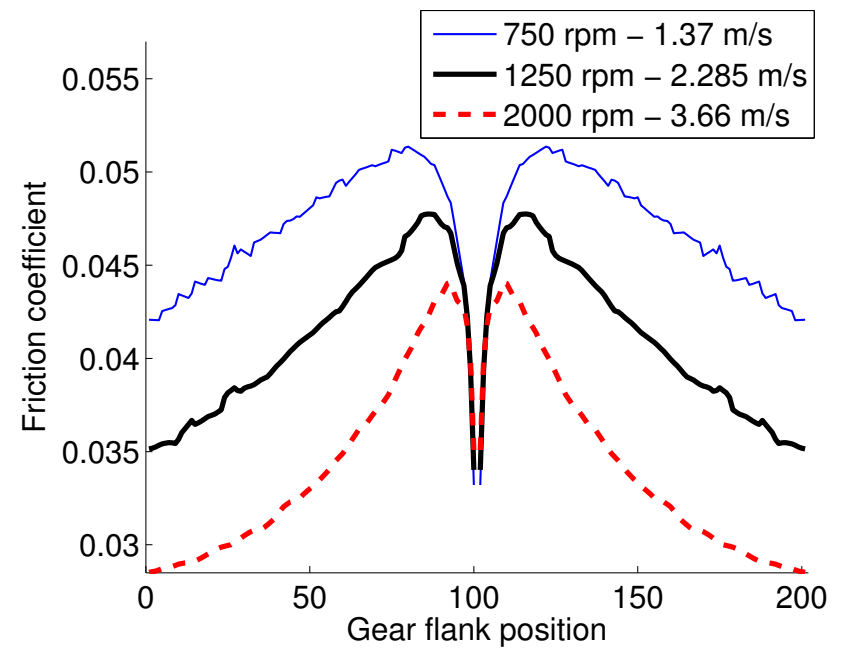

Figure 4: Friction coefficients simulated in ball on disc machine along the line of action at three different rotational speeds for Emgard oil at $40^{\circ} \mathrm{C}$. 
packages. Furthermore, the shape of the friction curves are relatively similar between the test rigs indicating that the ball on disc measurements are reasonably well capturing the behaviour of the gear contact. The agreements between the ball on disc measurements and the gear tests are well in line with, or better than comparisons between twin disc and gears found in literature [10, 11, 15].

However, there is a difference in absolute friction values between the ball on disc and gear tests. One of the reasons are most likely the simplification of using only one pressure level in the ball on disc measurements to make the use of friction mapping possible. This pressure corresponds to the pressure in the gear contact when only one tooth is carrying the load. In parts along the line of action where two teeth are carrying the load, the pressure will be lower and the friction coefficients will drop due to the reduction in pressure. This is one reason for the ball on disc friction values to be slightly higher than the values from the gear test, which is also the general case in Figs. 5 and 6 . Moreover, the deviations generally increase with rotational speed which is most likely caused by different thermal properties of the two systems. It is expected that thermal effects will increase more with rotational speed in the gear setup than in the ball on disc setup due to the higher frictional power generated in the gear rig.

Although the correlation between the gear tests and the ball on disc tests are not always spot on in terms of absolute friction coefficients, the shape of the friction curves are similar in both cases. Moreover, the differences between the oils are maintained for the two different rigs, at both temperatures, suggesting that the use of friction testing in a ball on disc machine could be a good alternative to a full gear test for evaluating lubricants in terms of friction performance. In addition, the use of the friction mapping concepts gives a gear developer the possibility to assess an approximate friction coefficient for a type of gear with a specific set of entrainment speeds and SRRs without having to manufacture such a gear. A new gear pair at a specific rotational speed will cover a different set of entrainment speeds and SRRs compared to the examples given in figure 2. and if the friction map is sufficiently large, an enormous amount of different gear geometries and rotational speeds could be assessed without having to run 


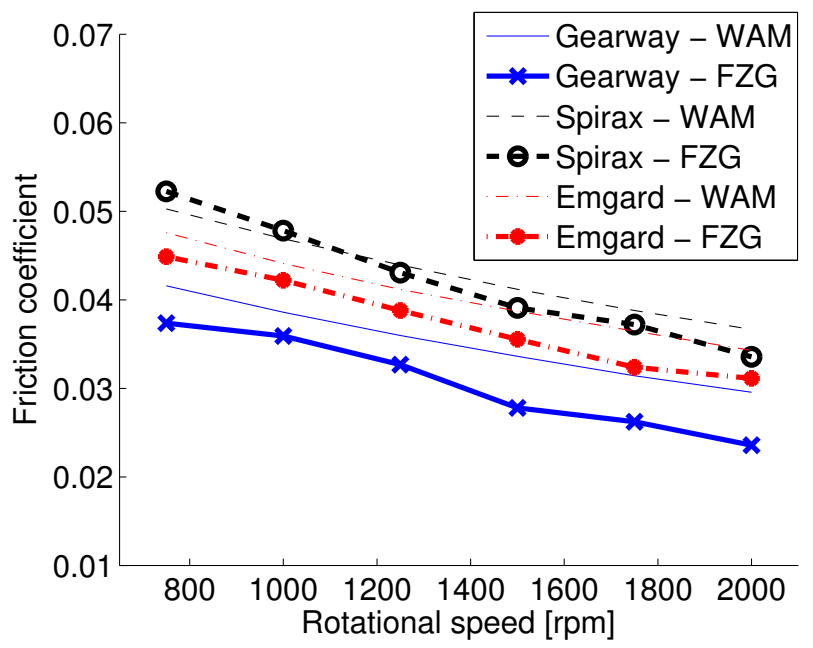

Figure 5: Friction coefficients for ball on disc and gear tests for three different lubricants conducted at an oil temperature of $40^{\circ} \mathrm{C}$.

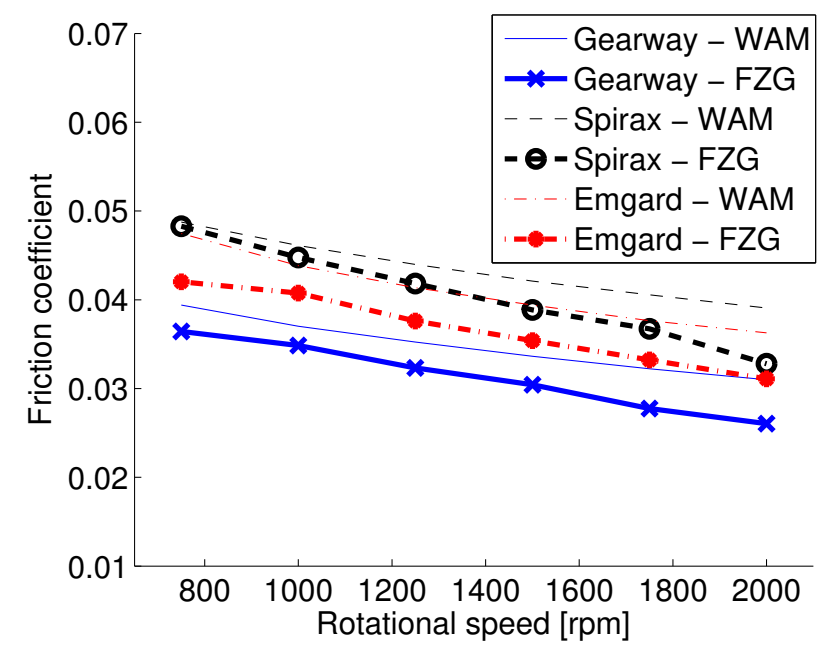

Figure 6: Friction coefficients for ball on disc and gear tests for three different lubricants conducted at an oil temperature of $70^{\circ} \mathrm{C}$. 
any more ball on disc tests. The exception being large differences in contact pressures that could possibly occur when changing gear geometries requiring another ball on disc test to be performed at another contact pressure level.

\section{In conclusion}

The objective of this work was to investigate if it is possible to use a ball on disc machine creating a circular EHD contact to assess the contact friction in a spur gear line contact. The ball on disc machine was used to measure friction in a range of entrainment speeds and SRRs that includes the corresponding values calculated for the gear pair at a certain range of rotational speeds. The ball on disc measurements were then used to calculate an average contact friction coefficient along the line of action of the corresponding gear pair at a certain rotational speed. This average friction coefficient was then compared to an average friction coefficient obtained in the gear test rig. The correlation between the gear tests and the ball on disc tests were reasonably good in terms of absolute values, and the shape of the friction curves were similar between the tests rigs indicating that the ball on disc measurements to a large extent were capturing the behaviour of the gear contact. The ranking between the oils were the same in the two test rigs at both oil temperatures. These findings brings forward the possibility to perform cheaper tests in a ball on disc machine to evaluate different lubricants in terms of friction performance compared to full gear tests. Furthermore, using the friction mapping approach presented in this work also gives the possibility to assess the contact friction losses in several theoretical gear pairs with different geometries by performing a small amount of ball on disc tests for each investigated lubricant. Further investigations are required to explore if the same conclusions could be drawn from systems using other base oil types and rougher surfaces. 


\section{Acknowledgments}

The authors gratefully acknowledge industrial partners Volvo Construction Equipment, Scania and Vicura AB for support, and Swedish Foundation for Strategic Research (SSF) and ProViking for financial support. The authors would also like to thank Scania and Statoil Fuel \& Retail for providing the test lubricants.

\section{References}

[1] K. Holmberg, P. Andersson, A. Erdemir, Global energy consumption due to friction in passenger cars, Tribology International 47 (2012) 221-234. doi:10.1016/j.triboint.2011.11.022.

[2] K. Holmberg, P. Andersson, N. O. Nylund, K. Mkel, A. Erdemir, Global energy consumption due to friction in trucks and buses, Tribology International 78 (2014) 94-114. doi:10.1016/j.triboint.2014.05.004.

[3] C. Changenet, Power loss predictions in geared transmissions using thermal networks-applications to a six-speed manual gearbox, Journal of Mechanical Design, Transactions of the ASME 128 (2006) 618-625. doi: $10.1115 / 1.2181601$

[4] K. F. Martin, The efficiency of involute spur gears, Journal of Mechanical Design 103(1) (1981) 160-169. doi:10.1115/1.3254855.

[5] D. Y. Hua, M. M. Khonsari, Application of transient elastohydrodynamic lubrication analysis for gear transmissions, Tribology Transactions 38(4) (1995) 905-913.

[6] S. Wu, H. S. Cheng, A friction model of partial-EHL contacts and its application to power loss in spur gears, Tribology Transactions 34(3) (1991) 398-407. 
[7] H. Xu, A. Kahraman, N. E. Anderson, D. G. Maddock, Prediction of mechanical efficiency of parallel-axis gear pairs, Journal of Mechanical Design 129 (2007) 58-68. doi:10.1115/1.2359478.

[8] S. Akbarzadeh, M. M. Khonsari, Performance of spur gears considering surface roughness and shear thinning lubricant, Journal of Tribology 130 (2008) 021503.1-021503.8. doi:10.1115/1.2805431.

[9] M. Björling, W. Habchi, S. Bair, R. Larsson, P. Marklund, Towards the true prediction of EHL friction, Tribology International 66 (2013) 19-26. doi:10.1016/j.triboint.2013.04.008.

[10] B.-R. Höhn, K. Michaelis, A. Doleschel, Frictional behaviour of synthetic gear lubricants, Tribology Series 39 (2001) 759-768.

[11] B.-R. Höhn, K. Michaelis, A. Doleschel, Limitations of bench testing for gear lubricants, ASTM Special Technical Publication 1404 (2001) 15-32.

[12] R. I. Amaro, R. C. Martins, J. O. Seabra, S. Yang, D. G. Teer, N. M. Renevier, Carbon/chromium low friction surface coating for gears application, Industrial Lubrication and Tribology 57(6) (2005) 233-242. doi: $10.1108 / 00368790510622326$

[13] J. Castro, J. Seabra, Coefficient of friction in mixed film lubrication: gears versus twin-discs, Proceedings of the Institution of Mechanical Engineers, Part J: Journal of Engineering Tribology 221(3) (2007) 399-411. doi: 10.1243/13506501JET257.

[14] J. Kleemola, A. Lehtovaara, Experimental evaluation of friction between contacting discs for the simulation of gear contact, Tribo test 13(1) (2007) 13-20. doi:10.1002/tt.29.

[15] J. Kleemola, A. Lehtovaara, Experimental simulation of gear contact along the line of action, Tribology International 42(10) (2009) 1453-1459. doi: 10.1016/j.triboint.2009.06.007 
[16] M. Björling, R. Larsson, P. Marklund, E. Kassfeldt, Elastohydrodynamic lubrication friction mapping - the influence of lubricant, roughness, speed, and slide-to-roll ratio, Proceedings of the Institution of Mechanical Engineers, Part J: Journal of Engineering Tribology 225(7) (2011) 671-681. doi:10.1177/1350650111403363.

[17] SKF - Rolling bearings catalogue, SKF Group, 2012.

[18] K. Michaelis, B. R. Höhn, Influence of lubricants on power loss of cylindrical gears, Tribology Transactions 37(1) (1994) 161-167. doi:10.1080/ 10402009408983279

[19] W. Habchi, S. Bair, P. Vergne, On friction regimes in quantitative elastohydrodynamics, Tribology International 58 (2013) 107-117. doi:10.1016/ j.triboint.2012.10.005. 